\title{
Natural Radioactivity and External Dose Assessment of Surface Soils in Bolikhamxay Province, Laos
}

\author{
Somsavath Leuangtakoun ${ }^{1,2, *}$, Bui Van Loat ${ }^{1}$, \\ Vu Thi Kim Duyen ${ }^{3}$, Khong Nam Khang ${ }^{4}$ \\ ${ }^{l}$ Department of Nuclear Physics, Faculty of Physics, VNU University of Science, \\ 334 Nguyen Trai, Hanoi, Vietnam \\ ${ }^{2}$ National University of Laos, P.O.Box: 7322, Dongdok Vientiane, Laos \\ ${ }^{3}$ Centre for Env.Trea. Tech., Ministry of Defence, 282 Lac Long Quan, Hanoi, Vietnam \\ ${ }^{4}$ Military Institute of Medical Radiology and Oncology \\ Received 15 August 2017 \\ Revised 23 October 2017; Accepted 25 October 2017
}

\begin{abstract}
We have determined activity concentrations in 33 soil samples collected from Bolikhamxay Province, Laos. The activity concentrations of the natural radionuclides ${ }^{226} \mathrm{Ra},{ }^{232} \mathrm{Th}$ and ${ }^{40} \mathrm{~K}$ in soil samples were measured by a gamma spectrometer with a HPGe detector. The average activity concentrations of the natural radionuclides ${ }^{226} \mathrm{Ra},{ }^{232} \mathrm{Th}$ and ${ }^{40} \mathrm{~K}$ are $43.8 \pm 5.6$, $57.0 \pm 7.3$ and $426.4 \pm 23.1 \mathrm{~Bq} \cdot \mathrm{kg}^{-1}$, respectively. The average activity concentrations of ${ }^{226} \mathrm{Ra}$ and ${ }^{232} \mathrm{Th}$ in this work are higher than those of the world average values. Meanwhile, the activity concentration of ${ }^{40} \mathrm{~K}$ is almost the same of the world average value. The estimated average outdoor annual effective dose $(\mathrm{E})$ and radium equivalent actitvity $\left(\mathrm{Ra}_{\mathrm{eq}}\right)$ are $0.17 \pm 0.02 \mathrm{mSv} \cdot \mathrm{yr}^{-1}$ and $154.8 \pm 16.1 \mathrm{~Bq} \cdot \mathrm{kg}^{-1}$, respectively.

Keywords: Gamma spectrometry, Activity concentration, Radium Equivalent Activity, Absorbed gamma dose rate, Annual effective dose rate, Minimum Detection Limit.
\end{abstract}

\section{Introduction}

Natural radioactivity is widespread in the earth's environment, it exists in the soil, plants, water, and airs. The gamma radiation from natural radionuclides and cosmic rays constitute the external exposure. Natural radionuclides in the soil generate a significant component of the background radiation exposure to the population [1, 2]. Radionuclides in soils, belonging to the ${ }^{226} \mathrm{Ra}$ and ${ }^{232} \mathrm{Th}$ series, as well as radioisotope of the potassium $\left({ }^{40} \mathrm{~K}\right)$, are the major contributors of outdoor terrestrial natural radiation [3]. Natural radioactivity depends primarily on the geological and geographical conditions, and appears at the different level in the soils of each region in the world (UNSCEAR,2000)

\footnotetext{
* Corresponding author. Tel.: 84-912865869.

Email: s.leuangtakoun@nuol.edu.la

https//doi.org/ 10.25073/2588-1124/vnumap.4224
} 
[1]. Our present study aimed at the determining of the natural radionuclides levels, evaluating radiation hazard indices and the effective dose to the public from soil samples in Bolikhamxay Provine,Laos.

\section{Materials and methods}

\subsection{Study area}

Bolikhamxayis a province of Laos, located in the middle of the country on latitude $18.4363^{\circ} \mathrm{N}$ and longitude $104.4723^{\circ} E$ as shown in Figure 1. The altitude ranges from 140- 1,588 metres an area of 15,977 square kilometers. The population of 190.000, rich of culture and nature resource with 3 national protected areas: PhouKhaoKhouay, NamKaDing and a part of Theun-Nakai. 'Pakxan' the capital of Bolikhamxay lies some 150km by South 13 Road from Vientiane.

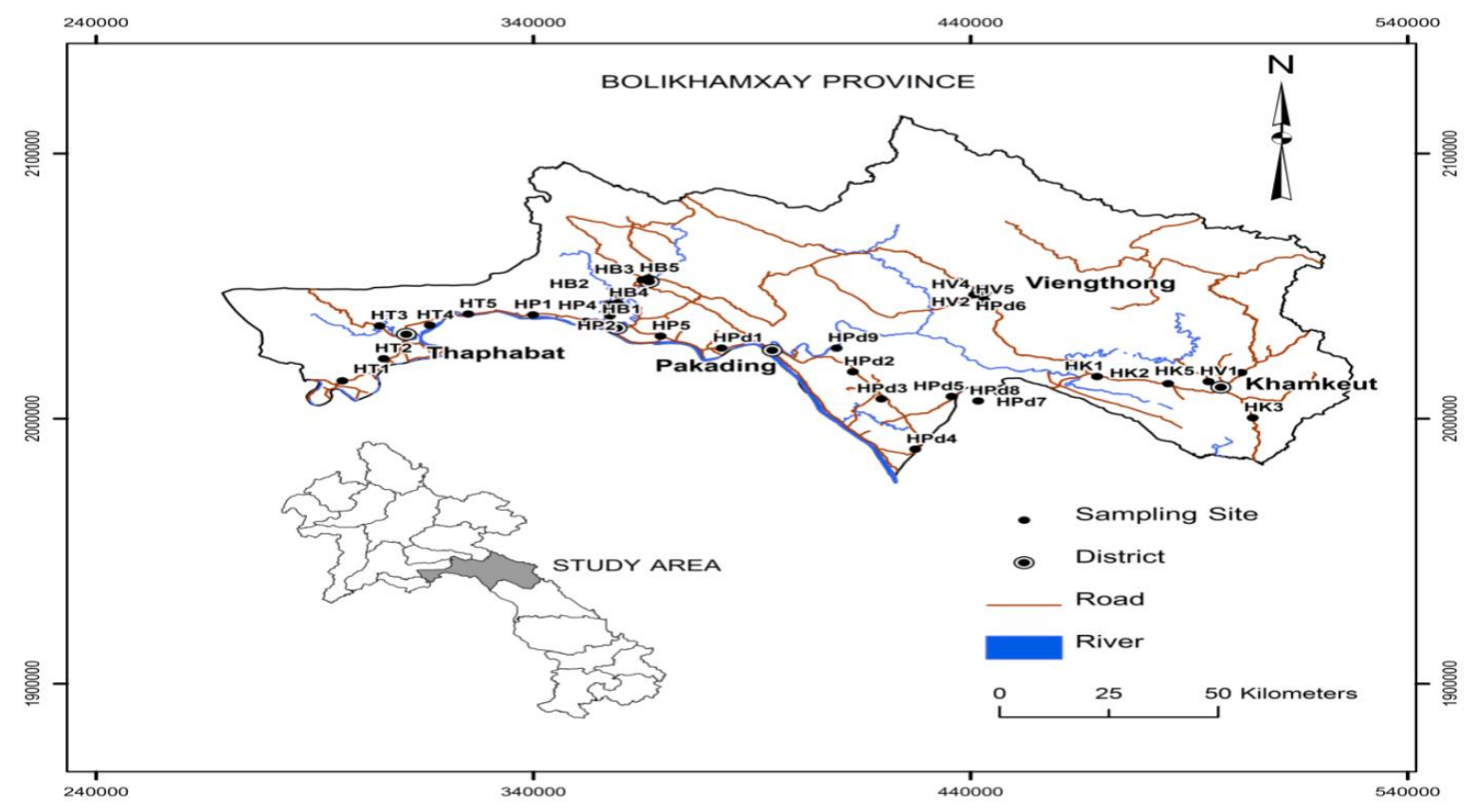

Figure 1. Sampling location in Bolikhamxay Province, Laos.

\subsection{Preparation and processing of soil samples}

Soil samples were collected from 33 different locations in Bolikhamxay province that are close to the populated areas and agriculture field. At every sampling site, the soil samples were collected from the surface layers (5-15 cm depth) using a spade.-Organic materials, piece of stones in samples were romoved. At the laboratory,the samples were dried in an oven at about $110{ }^{\circ} \mathrm{C}$ for 6 hours. After drying, the samples were crushed and served with a mesh having holes each of diameter of $0.2 \mathrm{~mm}$.

Afterward, the homogenized samples were weighed and each sample was packed in a cylindrical plastic container of height $3 \mathrm{~cm}$ and $7.0 \mathrm{~cm}$ diameter. These were then stored for at least one month to ensure secular equilibrium between the parent radionuclides and their respective daughters. 


\subsection{Experimental determination of radiation hazards}

\subsubsection{Determination of activity concentration}

The activity concentration of a certain radionuclide, $A_{0}$, in the soil samples was calculated using the following equation $[4,5]$ :

$$
\mathrm{A}_{0}\left(\mathrm{Bqkg}^{-1}\right)=\frac{n}{\varepsilon \times I_{\text {eff }} \times m_{s}}
$$

here $n$ is the net gamma counting rate (counts per second) for a peak at energy E, $\varepsilon$ is the detected efficiency of a specific $\gamma$ ray, $I_{\text {eff }}$ is the intensity of the $\gamma$ line in radionuclides, and $m_{g}$ is the mass of the soil sample under consideration measured in kilograms.

In this work, gamma spectra of samples were measured by low level gamma spectrometer (CANBERRA) using the high purity germanium detector (HPGe) with relative efficiency of $15 \%$ and energy resolution of $1.66 \mathrm{keV}$ at $1332 \mathrm{keV}$ peak of ${ }^{60} \mathrm{Co}$. The detector is placed in a thick lead shield to reduce gamma radiation background to meet environmental standards to below 0.9 pulses $/ \mathrm{sec}$ in the energy region from $100 \mathrm{keV}$ to $3000 \mathrm{keV}$. The activity of ${ }^{226} \mathrm{Ra}$ was determined based on 295.57 and $351.9 \mathrm{keV}$ photopeaks, emitted from ${ }^{214} \mathrm{~Pb}$, and $609.3 \mathrm{keV}$ and $1120.3 \mathrm{keV}$ peak in turn from ${ }^{214} \mathrm{Bi}$. The activity of ${ }^{232} \mathrm{Th}$ was extracted by 338.6 and $911.1 \mathrm{keV}$ gamma rays of ${ }^{228} \mathrm{Ac}$ and $583.19 \mathrm{keV}$ gamma ray of ${ }^{208} \mathrm{Tl}$, respectively. The activity of ${ }^{40} \mathrm{~K}$ was determined by $1460.82 \mathrm{keV}$ gamma ray.

\subsubsection{Radium equivalent activity}

The distribution of ${ }^{226} \mathrm{Ra},{ }^{232} \mathrm{Th}$ and ${ }^{40} \mathrm{~K}$ in soil is not uniform. Uniformity with respect to exposure to radiation has been defined in terms of radium equivalent activity $\left(\mathrm{Ra}_{\mathrm{eq}}\right)$ in $\mathrm{Bq} \cdot \mathrm{kg}^{-1}$ to compare the specific activity of materials containing different amounts of ${ }^{226} \mathrm{Ra},{ }^{232} \mathrm{Th}$ and ${ }^{40} \mathrm{~K}$ [6]. It is calculated through the following relation:

$$
\mathrm{Ra}_{\mathrm{eq}}=\mathrm{A}_{0 \mathrm{Ra}}+1.43 \mathrm{~A}_{0 \mathrm{Th}}+0.07 \mathrm{~A}_{0 \mathrm{~K}}
$$

where $\mathrm{A}_{0 \mathrm{Ra}}, \mathrm{A}_{0 \mathrm{Th}}$ and $\mathrm{A}_{0 \mathrm{~K}}$ are the activity concentration of ${ }^{226} \mathrm{Ra},{ }^{232} \mathrm{Th}$ and ${ }^{40} \mathrm{~K}$ in $\mathrm{Bq} \cdot \mathrm{kg}^{1}$, respectively.

Absorbed gamma dose rate (D): The outdoor absorbed dose rate $\left(\mathrm{nGyh}^{-1}\right)$ in air from terrestrial gamma radiation at $1 \mathrm{~m}$ above the ground is calculated after applying the conversion factors (in $\mathrm{nGyh}^{-1}$ per $\mathrm{Bq} \cdot \mathrm{kg}^{-1}$ ) to transform the specific activities $\mathrm{A}_{0 \mathrm{Ra}}, \mathrm{A}_{0 \mathrm{Th}}$ and $\mathrm{A}_{0 \mathrm{~K}}$ into the absorbed dose rate according to the formula provided by UNSCEAR [1]:

$$
\mathrm{D}\left(\mathrm{nGyh}^{-1}\right)=0.92 \times \mathrm{A}_{0 \mathrm{Ra}}+1.1 \times \mathrm{A}_{0 \mathrm{Th}}+0.080 \times \mathrm{A}_{0 \mathrm{~K}}
$$

where $A_{0 \text { Ra }}, A_{0 T h}$, and $A_{0 \mathrm{~K}}$ are the activity concentration of ${ }^{226} \mathrm{Ra},{ }^{232} \mathrm{Th}$ and ${ }^{40} \mathrm{~K}$ in $\left(\mathrm{Bq} \cdot \mathrm{kg}^{-1}\right)$, respectively.

Absorbed gamma dose rate were used to estimate the annual effective dose rate. It is necessary to use the conversion coefficient from the absorbed dose in air to the effective dose $\left(0.7 \mathrm{SvGy}^{-1}\right)$ and the outdoor occupancy factor $\left(0.2 \mathrm{SvGy}^{-1}\right)$ proposed by UNSCEAR [1]. Therefore, the outdoor effective dose rate is determined as follows:

$$
\begin{array}{ccc} 
& \mathrm{E}\left(\mathrm{mSvy}^{-1}\right)=\mathrm{D}\left(\mathrm{nGyh}^{-1}\right) \times 8760 \mathrm{~h} \times 0.2 \times 0.7 \mathrm{SvGy}^{-1} \times 10^{-6} \\
\text { or } & \mathrm{E}\left(\mathrm{mSvy}^{-1}\right)=\mathrm{D}\left(\mathrm{nGyh}^{-1}\right) \times 0.00123
\end{array}
$$

where $D$ is the dose rate in $n G y . h^{-1}$. 


\subsubsection{External and internal Hazard index}

External Hazard Index $\mathrm{H}_{\mathrm{ex}}$ : Radiation exposure due to ${ }^{226} \mathrm{Ra},{ }^{232} \mathrm{Th}$ and ${ }^{40} \mathrm{~K}$ may be external. This hazard defined in terms of external or outdoor radiation hazard index and denoted by $\mathrm{H}_{\mathrm{ex}}$, can be calculated using equation [7]:

$\mathrm{H}_{\mathrm{ex}}=\mathrm{A}_{0 \mathrm{Ra}} / 370+\mathrm{A}_{0 \mathrm{Th}} / 259+\mathrm{A}_{0 \mathrm{~K}} / 4810$

Internal Hazard Index $\left(H_{\text {in }}\right)$ : Internal hazard index $\left(H_{\text {in }}\right)$ is given by equation [7]: $\mathrm{H}_{\text {in }}=\mathrm{A}_{0 \mathrm{Ra}} / 185+\mathrm{A}_{0 \mathrm{Th}} / 259+\mathrm{A}_{0 \mathrm{~K}} / 4810$

$\mathrm{H}_{\mathrm{in}}$ must be less than one for safe use of samples and for the radiation hazard to be negligible.

\section{Result and discussion}

\subsection{Activity concentration in soil samples}

The activity concentrations of radionuclides have been determined by gamma spectrometry technique for 33 soil samples collected from Bolikhamxay province in Laos. The sampling locations were close to the populated areas and agricultural land. The results of activity concentration for the radionuclides ${ }^{226} \mathrm{Ra},{ }^{232} \mathrm{Th}$ and ${ }^{40} \mathrm{~K}$ are shown graphically in Figure 1a, Figure1b, Figure 1c, respectively.

\subsubsection{Activity concentration of ${ }^{226} R a$}

The concentration of ${ }^{226} \mathrm{Ra}$ ranges from13.03 $\pm 1.32 \mathrm{~Bq} \cdot \mathrm{kg}^{-1}$ to $90.8 \pm 12.8 \mathrm{~Bq} \cdot \mathrm{kg}^{-1}$. The lowest ${ }^{226} \mathrm{Ra}$ activity concentration of $13.03 \pm 1.32 \mathrm{~Bq} \cdot \mathrm{kg}^{-1}$ was found in HP4 sample .The highest value for ${ }^{226} \mathrm{Ra}\left(90.75 \pm 10.37 \mathrm{~Bq} \cdot \mathrm{kg}^{-1}\right)$ was found in $\mathrm{HB} 4$ sample, Figure 2a. The average radioactivity level for ${ }^{226} \mathrm{Ra}\left(43.8 \pm 5.6 \mathrm{~Bq} \cdot \mathrm{kg}^{-1}\right)$ is higher than the world average value of $35 \mathrm{~Bq} \cdot \mathrm{kg}^{-1}[1]$.

\subsubsection{Activity concentration of ${ }^{232} \mathrm{Th}$}

The ${ }^{232} \mathrm{Th}$ radioactivity concentration varies from $11.12 \pm 1.2$ to $93.15 \pm 10.2 \mathrm{~Bq} \cdot \mathrm{kg}^{-1}$. The lowest ${ }^{232} \mathrm{Th}$ activity concentration of $11.12 \pm 1.2 \mathrm{~Bq} \cdot \mathrm{kg}^{-1}$ was found in HP4. The highest ${ }^{232} \mathrm{Th}$ activity of $93.15 \pm 10.2 \mathrm{~Bq} \cdot \mathrm{kg}^{-1}$ was found in the HB3, Figure $2 \mathrm{~b}$. The average radioactivity level of ${ }^{232} \mathrm{Th}$ of $57.0 \pm 7.3 \mathrm{~Bq} \cdot \mathrm{kg}^{-1}$ is also higher than the world average of $30 \mathrm{~Bq} \cdot \mathrm{kg}^{-1}$ [1].

\subsubsection{Activity concentration of ${ }^{40} \mathrm{~K}$}

The activity concentration of ${ }^{40} \mathrm{~K}$ ranges from $37.5 \pm 2.7$ to $979.1 \pm 31.7 \mathrm{~Bq} \cdot \mathrm{kg}^{-1}$. The lowest ${ }^{40} \mathrm{~K}$ activity concentration of $37.5 \pm 2.7 \mathrm{~Bq} \cdot \mathrm{kg}^{-1}$ was found in $\mathrm{HPd} 3$. The highest ${ }^{40} \mathrm{~K}$ activity concentration of $979.1 \pm 31.7$ Bq. $\mathrm{kg}^{-1}$ was found in HT4, Figure $2 \mathrm{c}$. The average value of ${ }^{40} \mathrm{~K}$ is $413.9 \pm 22.4 \mathrm{~Bq} \cdot \mathrm{kg}^{-1}$. This value is the same in the world average of $400 \mathrm{~Bq} \cdot \mathrm{kg}^{-1}$ [1].

\subsection{Radiological hazard assessment}

In order to assess the health effects, the absorbed does rate, outdoor annual effective dose, external hazard index and internal hazard index have been calculated from the activity concentrations of ${ }^{226} \mathrm{Ra},{ }^{232} \mathrm{Th}$ and ${ }^{40} \mathrm{~K}$ using equations (3), (4), (5), (6), respectively.The results shown in Table 1 depict that the absorbed does rates due to the terrestrial gamma rays at $1 \mathrm{~m}$ above from the ground are in the range of 34.91 to $226.07 \mathrm{nGyh}^{-1}$ with an average of $136.1 \mathrm{nGyh}^{-1}$. This value is about two times higher than the world average value of $59 \mathrm{nGy} \cdot \mathrm{h}^{-1}$ [1]. The outdoor annual effective dose rates are in the range of 0.04 to $0.28 \mathrm{mSv} \cdot \mathrm{y}^{-1}$ with an average of $0.17 \mathrm{mSv} \cdot \mathrm{y}^{-1}$ in the soil samples, which is higher than comparable with the world average value of $0.07 \mathrm{mSv}_{\mathrm{yr}} \mathrm{r}^{-1}$ [1]. On the other hand, the calculated values of the external radiation hazard index range from 0.11 to 0.70 with an average value of 0.42 and the internal radiation hazard index range from 0.14 to 0.89 with an average value of 0.54 which are far less than unity indicating the non - hazardous category of the samples. 

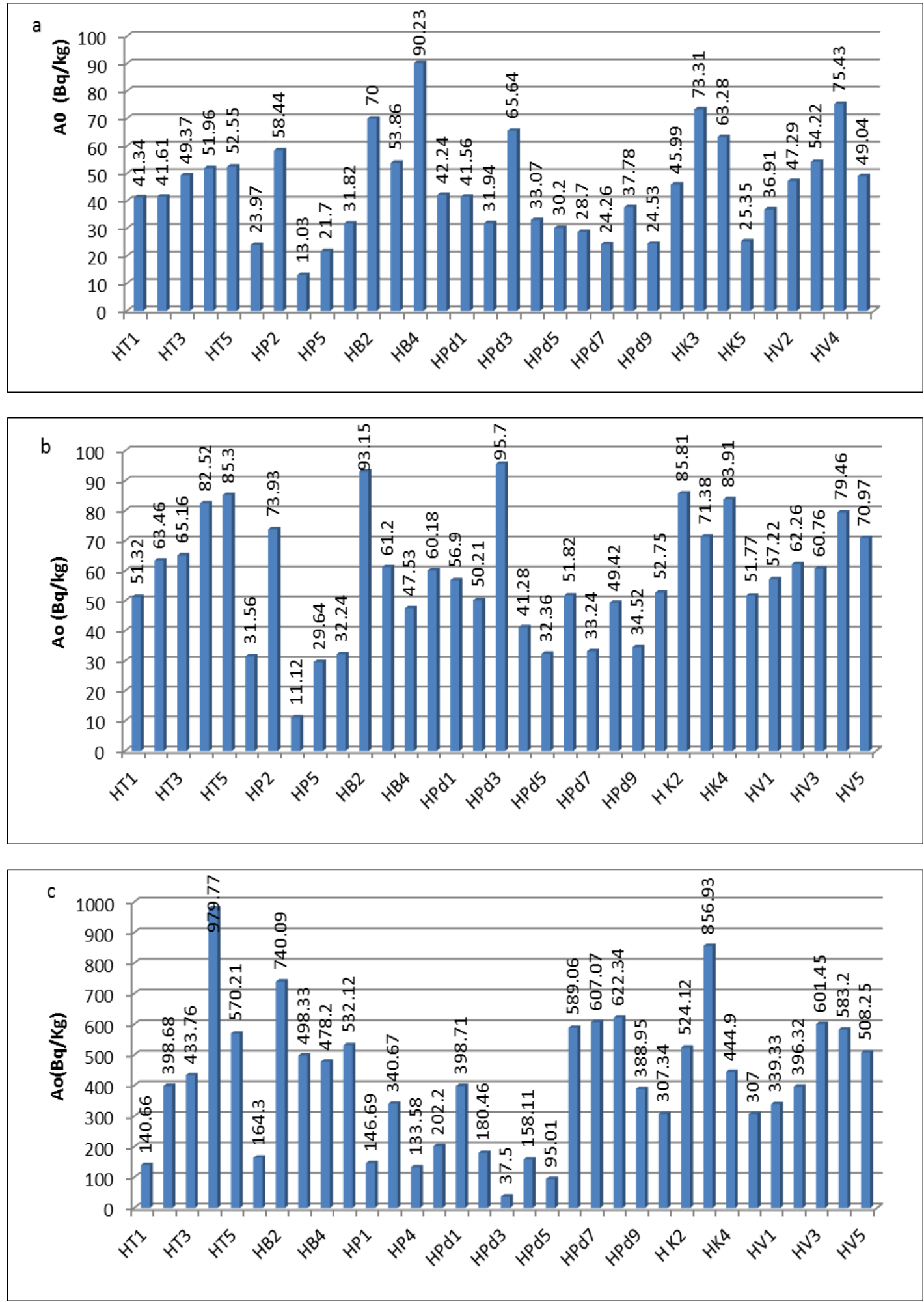

Fig.2. Activity concentration of ${ }^{226} \mathrm{Ra},{ }^{232} \mathrm{Th}$ and ${ }^{40} \mathrm{~K}$ in soil samples: a. ${ }^{226} \mathrm{Ra}, \mathrm{b} .{ }^{232} \mathrm{Th}$ and c. ${ }^{40} \mathrm{~K}$. 
Table 1. Radium equivalent $\left(\mathrm{Ra}_{\mathrm{eq}}\right)$, gamma-ray absorbed does, annual effective does, external and internalhazard index from the surface soil samples collected from Bolikhamxay province, Laos.

\begin{tabular}{|c|c|c|c|c|c|}
\hline $\begin{array}{l}\text { Sample } \\
\text { code }\end{array}$ & $\mathrm{Ra}_{\mathrm{eq}}\left(\mathrm{Bqkg}^{-1}\right)$ & $\begin{array}{l}\text { Absorbed } \\
\text { Does rate } \\
\mathrm{nGyh}^{-1}\end{array}$ & $\begin{array}{l}\text { Annual } \\
\text { Effective dose } \\
E(m S v / y)\end{array}$ & $\begin{array}{l}\text { External hazard } \\
\text { index }\left(\mathrm{H}_{\mathrm{ex}}\right)\end{array}$ & $\begin{array}{l}\text { Internal hazard } \\
\text { index }\left(\mathrm{H}_{\mathrm{in}}\right)\end{array}$ \\
\hline HT1 & $124.57 \pm 12.61$ & $105.74 \pm 15.40$ & $0.13 \pm 0.02$ & $0.34 \pm 0.04$ & $0.45 \pm 0.06$ \\
\hline HT2 & $160.27 \pm 17.05$ & $139.98 \pm 18.43$ & $0.17 \pm 0.02$ & $0.44 \pm 0.05$ & $0.55 \pm 0.07$ \\
\hline HT3 & $172.91 \pm 18.07$ & $151.80 \pm 18.68$ & $0.19 \pm 0.02$ & $0.48 \pm 0.05$ & $0.61 \pm 0.08$ \\
\hline HT4 & $178.11 \pm 18.51$ & $105.74 \pm 11.76$ & $0.13 \pm 0.02$ & $0.34 \pm 0.04$ & $0.45 \pm 0.06$ \\
\hline HT5 & $214.44 \pm 24.23$ & $187.79 \pm 21.91$ & $0.23 \pm 0.03$ & $0.59 \pm 0.07$ & $0.73 \pm 0.09$ \\
\hline HP1 & $79.37 \pm 9.26$ & $68.50 \pm 8.63$ & $0.08 \pm 0.01$ & $0.22 \pm 0.05$ & $0.28 \pm 0.04$ \\
\hline HP2 & $188.01 \pm 10.24$ & $162.34 \pm 8.61$ & $0.20 \pm 0.02$ & $0.51 \pm 0.02$ & $0.67 \pm 0.09$ \\
\hline HP4 & $73.36 \pm 26.11$ & $65.27 \pm 8.80$ & $0.08 \pm 0.01$ & $0.20 \pm 0.07$ & $0.27 \pm 0.04$ \\
\hline HP5 & $121.96 \pm 10.06$ & $106.77 \pm 8.56$ & $0.13 \pm 0.01$ & $0.34 \pm 0.02$ & $0.43 \pm 0.05$ \\
\hline HB 1 & $89.42 \pm 6.28$ & $77.88 \pm 8.30$ & $0.10 \pm 0.01$ & $0.24 \pm 0.02$ & $0.33 \pm 0.04$ \\
\hline $\mathrm{HB} 2$ & $255.01 \pm 33.87$ & $226.07 \pm 28.63$ & $0.28 \pm 0.03$ & $0.70 \pm 0.08$ & $0.89 \pm 0.12$ \\
\hline HB3 & $220.84 \pm 28.27$ & $199.14 \pm 21.75$ & $0.24 \pm 0.03$ & $0.61 \pm 0.07$ & $0.79 \pm 0.11$ \\
\hline HB4 & $192.19 \pm 21.78$ & $174.03 \pm 20.18$ & $0.21 \pm 0.03$ & $0.53 \pm 0.07$ & $0.77 \pm 0.11$ \\
\hline HB5 & $146.91 \pm 17.06$ & $130.63 \pm 14.53$ & $0.16 \pm 0.02$ & $0.40 \pm 0.04$ & $0.52 \pm 0.06$ \\
\hline HPd1 & $150.84 \pm 19.31$ & $132.72 \pm 14.42$ & $0.16 \pm 0.02$ & $0.41 \pm 0.05$ & $0.53 \pm 0.07$ \\
\hline $\operatorname{HPd} 2$ & $116.37 \pm 15.28$ & $99.05 \pm 12.74$ & $0.12 \pm 0.01$ & $0.32 \pm 0.04$ & $0.40 \pm 0.05$ \\
\hline $\mathrm{HPd} 3$ & $227.88 \pm 38.91$ & $189.44 \pm 25.83$ & $0.23 \pm 0.03$ & $0.62 \pm 0.08$ & $0.83 \pm 0.11$ \\
\hline $\mathrm{HPd} 4$ & $103.17 \pm 17.93$ & $88.48 \pm 9.69$ & $0.11 \pm 0.01$ & $0.28 \pm 0.03$ & $0.37 \pm 0.05$ \\
\hline $\mathrm{HPd} 5$ & $83.13 \pm 11.55$ & $70.98 \pm 8.91$ & $0.09 \pm 0.01$ & $0.23 \pm 0.03$ & $0.31 \pm 0.04$ \\
\hline HPd6 & $144.04 \pm 17.02$ & $130.53 \pm 14.60$ & $0.16 \pm 0.02$ & $0.40 \pm 0.04$ & $0.48 \pm 0.06$ \\
\hline $\operatorname{HPd} 7$ & $167.23 \pm 19.36$ & $153.89 \pm 16.79$ & $0.19 \pm 0.02$ & $0.47 \pm 0.05$ & $0.56 \pm 0.07$ \\
\hline $\operatorname{HPd} 8$ & $152.01 \pm 17.84$ & $138.91 \pm 14.45$ & $0.17 \pm 0.02$ & $0.42 \pm 0.05$ & $0.52 \pm 0.06$ \\
\hline HPd9 & $101.12 \pm 12.04$ & $91.66 \pm 10.36$ & $0.11 \pm 0.01$ & $0.28 \pm 0.03$ & $0.35 \pm 0.04$ \\
\hline HK1 & $139.96 \pm 19.51$ & $122.18 \pm 16.43$ & $0.15 \pm 0.02$ & $0.38 \pm 0.04$ & $0.50 \pm 0.06$ \\
\hline HK2 & $176.95 \pm 29.85$ & $160.63 \pm 18.59$ & $0.20 \pm 0.03$ & $0.49 \pm 0.06$ & $0.72 \pm 0.09$ \\
\hline HK3 & $235.37 \pm 32.41$ & $214.52 \pm 29.15$ & $0.26 \pm 0.03$ & $0.65 \pm 0.08$ & $0.85 \pm 0.11$ \\
\hline HK4 & $214.41 \pm 25.01$ & $186.11 \pm 21.12$ & $0.23 \pm 0.03$ & $0.59 \pm 0.08$ & $0.76 \pm 0.08$ \\
\hline HK5 & $120.87 \pm 13.01$ & $104.83 \pm 12.12$ & $0.13 \pm 0.02$ & $0.33 \pm 0.04$ & $0.40 \pm 0.05$ \\
\hline HV1 & $142.49 \pm 15.75$ & $124.05 \pm 13.16$ & $0.15 \pm 0.02$ & $0.39 \pm 0.04$ & $0.49 \pm 0.05$ \\
\hline $\mathrm{HV} 2$ & $164.06 \pm 17.84$ & $143.70 \pm 14.98$ & $0.18 \pm 0.02$ & $0.45 \pm 0.05$ & $0.58 \pm 0.06$ \\
\hline HV3 & $183.21 \pm 20.32$ & $164.83 \pm 17.17$ & $0.20 \pm 0.02$ & $0.51 \pm 0.05$ & $0.65 \pm 0.07$ \\
\hline HV4 & $212.07 \pm 21.94$ & $186.33 \pm 19.9$ & $0.23 \pm 0.03$ & $0.58 \pm 0.06$ & $0.75 \pm 0.08$ \\
\hline HV5 & $186.10 \pm 17.26$ & $163.84 \pm 20.83$ & $0.20 \pm 0.02$ & $0.51 \pm 0.06$ & $0.64 \pm 0.07$ \\
\hline Aver. & $158.75 \pm 16.10$ & $140.31 \pm 15.75$ & $0.17 \pm 0.02$ & $0.44 \pm 0.05$ & $0.56 \pm 0.07$ \\
\hline
\end{tabular}




\section{Conclusion}

In this work the natural radioactivities in 33 surface soil samples collected from Bolikhamxay province were determined using a gamma ray spectrometer with HPGe detector. The average radioactivity concentrations of ${ }^{226} \mathrm{Ra}$ and ${ }^{232} \mathrm{Th}$ are $46.73 \pm 5.92$ and $57.95 \pm 7.72 \mathrm{~Bq} / \mathrm{kg}$, which are higher than that of the world average values $(35 \mathrm{~Bq} / \mathrm{kg}$ and $30 \mathrm{~Bq} / \mathrm{kg}$ ) respectively . But activity concentrations of ${ }^{226} \mathrm{Ra}$ and ${ }^{232} \mathrm{Th}$ are less than the value average of Nghe An province [8], it shares borders with Bolikhamxay provinceof Laos. The activity concentration of ${ }^{137} \mathrm{Cs}$ was not found in any of samples from Bolikhamxay province, this means that it is lower than the minimum detection limit. The mean radium equivalent activity concentration, the mean external and internal hazard indices in the study areas were less than the world average [1].

\section{References}

[1] UNSCEAR United National Scientific Committee on the Effectsof Atomic Radiation Sources and Risks of Ionizing Radiation,Report to the General Assembly with Annexes, United Nations,New York, 2000.

[2] KarahanG,Bayulken A. Assessment of gamma dose rates around Istanbul (Turkey). J Environ Radioact 2000; 47:213-21.

[3] Erees FS, Aközcan S, Parlak Y, Çam S. Assessment of dose rates around Manisa (Turkey). Radiat Measure 2006;41:598-601.

[4] Dabayneh K, Mashal L, Hasan F. Radioactivity concentration in soil samples in the southern part of the WestBank, Palestine. RadiatProt Dos 2008; 131: 265-271.

[5] Abdel-Ghany H. Natural activities of ${ }^{238} \mathrm{U},{ }^{232} \mathrm{Th}$ and ${ }^{40} \mathrm{~K}$ in manganese ore. Am EnvSci 2010; 6: 90-94.

[6] Yu, K.N., Guan, Z.J., Stokes, M.J. and Young, E.C.M.,The assessment of natural radiation dose committed to the Hong Kong people.Journal of Environmental Radioactivity 17,31.(1992).

[7] Beretka, J. and J. Matthew, 1985. Natural radioactivityof Australian building materials, industrial wastesand by products. Health Physics Journal, 48: 87-95.

[8] N.Q.Huy et al.,Natural radioactivity and external does assessment of surcface soils in Vietnam.Radiation Protection Dosimetry (2012), Vol. 151, No. 3, pp. 522-531. 